\title{
Monitoring eye movements in nonlearning situations'
}

\author{
P. D. MCCORMACK, E. J. HALTRECHT ${ }^{2}$ AND T. E. HANHAH \\ CARLETON UNIVERSITY, OTTAWA, CANADA
}

One group of $S s$ was given two exposures of a 28-item verbal PA list and was required to attempt to learn by the method of recall. Another group was asked to pronounce the stimuli when they appeared alone. Eye movements were monitored throughout the task for all $S$ s. The findings were consistent with a two-stage interpretation of verbal PA learning.

In an earlier study (McCormack \& Haltrecht, 1966) eye movements of 19 male Ss were photographed throughout the course of their learning verbal pairedassociates (PA) by the recall method. Response viewingtime decreased while time spent viewing the stimulus increased with trials. These findings were interpreted as being consistent with a two-stage notion of verbal learning (Underwood \& Schulz, 1960), Ss presumably consolidating the responses during the initial or "response learning" phase and then connecting them to the appropriate stimuli during the second or "hook-up" stage. The validity of the two-stage notion received additional support in a later investigation (McCormack, Haltrecht, \& Hannah, 1966) where Ss were required to learn a different list on each of three days. The fixation functions of the earlier study were obtained consistently from day to day.

In the present investigation, two groups of Ss were presented with PA materials, one group being given a next-to-impossible learning task and the other being required only to pronounce the stimuli when they appeared alone. Should the fixation functions of the earlier investigations be obtained in this setting, they could not be interpreted as being consistent with a twostage conception.

\section{Subjects}

Ss were 20 male students of introductory psychology. None had any serious visual defects nor had they participated previously in a verbal learning experiment. Apparaius

$S$ was seated in a dental chair, the various attachments of which facilitated the recording of eye movements. The materials, CVCs with $\underline{m}^{\prime}$ values (Noble, 1961) within the range 1.80-1.93, were projected by means of a Carousel unit to a green-surfaced chalkboard $4.5 \mathrm{ft}$. from $\mathrm{S}$ and $8 \mathrm{ft}$. from the projector. The slides changed every 2 sec. and were arranged as if a PA experiment was being conducted by the recall method.

Eye movements were recorded by means of a headmounted eye-marker camera (Mackworth \& Thomas, 1962), consisting of a $2 \times 8 \mathrm{~mm}$ motion picture unit filming at a speed of 16 frames/sec., and a periscope that transmits a spot of light from the cornea to the film. The film when developed shows the PA slides, and superimposed upon each, a bright circular spot indicating the approximate position of actual fixation. The data were analyzed frame by frame by examining the S-R slides through a film-viewer.

\section{Procedure}

Ss were divided into two groups, the 15 of Group $L$ being required to attempt to learn the materials and the 14 of Group P being asked to pronounce the CVC stimuli when they appeared alone. For Group L a 28item list was prepared. On the first trial, the first seven S-R pairs were presented consecutively. During this study phase, $S$ was instructed to examine the pairs in an attempt to learn them. Following a 2-sec. interval, the seven stimuli were presented, with $\mathrm{S}$ attempting to recall the appropriate responses during this test phase. A 2-sec. interval was provided between the test and subsequent study period where seven new pairs were presented. $S$ was given a $1-\min$. rest at the end of the fourth study-test trial, at which point he had seen each of the 28 pairs once. During the next four trials the 28 pairs were repeated, and the session was terminated after the eighth trial. For Group $P$ the same set of materials was presented with Ss being instructed to examine the pairs and to be ready to pronounce one of each when it would be presented alone. Results and Discussion

The main findings are summarized in Fig. 1. Trials are shown along the abscissa while the ordinate represents mean number of frames per syllable-pair for those slides where Sand R appeared together. The upper pair of functions represent Group $L$ frames while the lower pair are those of Group P. Broken curves indicate response frames while solid curves depict stimulus frames.

The findings portrayed by Fig: 1 were examined by means of analysis of variance techniques. A statistically dependable Groups by Conditions by Trials interaction was revealed $(p<.05)$ which was mostly due to a reliable Conditions by Trials $(p<.025)$ interaction on the part of Group L. This in turn was mainly due to Group $L$ 's decreasing viewing time on the response and increasing viewing time on the stimulus over the first four trials. After the fourth trial, Group L Ss tended to revert to their earlier strategy of viewing the response out of proportion to the stimulus. This was not the case, however, in earlier investigations where stimulus viewing became predominant between trials 


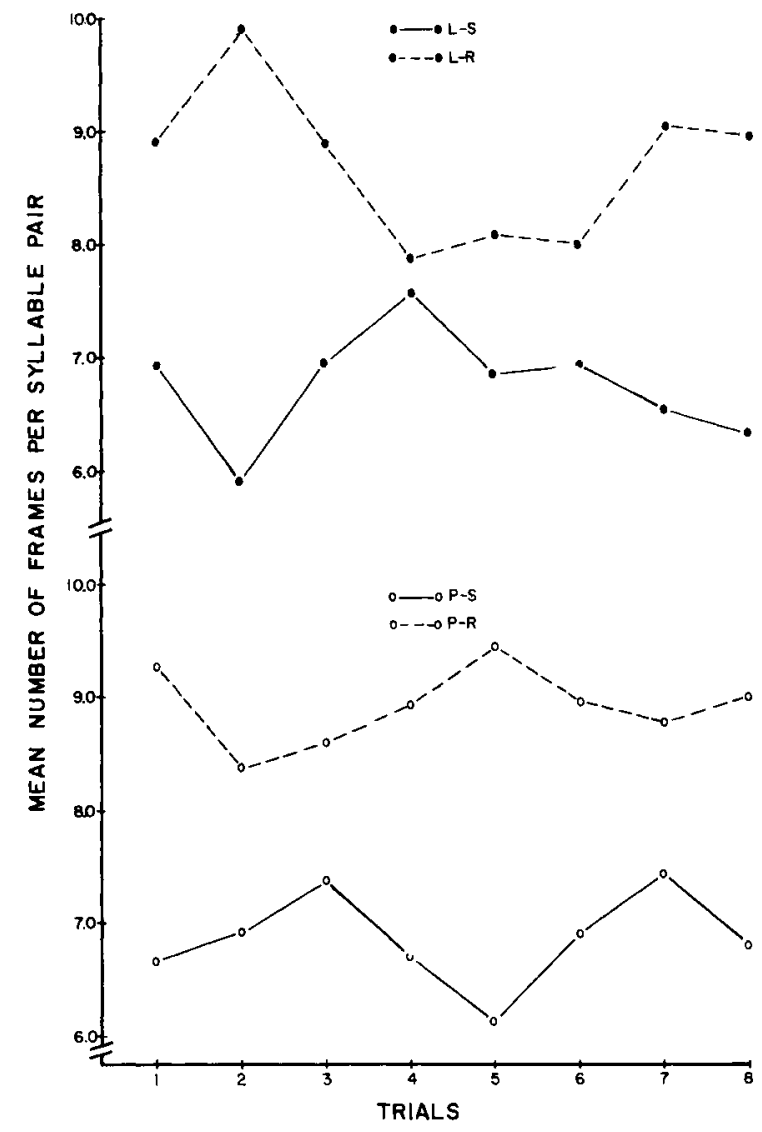

Fig. 1. Mean number of stimulus and response frames per syllable-pair as a function of trials for Groups $L$ and $P$.

3 and 4 in one case (McCormack \& Haltrecht, 1966) and between trials 2 and 3 in another (McCormack, Haltrecht, \& Hannah, 1966). At first glance, the decreasing viewing time on response and increasing viewing time on the stimulus shown by Ss of Group L during the first four trials, even though they had seen each CVC pair only once, seems to contradict the twostage conception. Further reflection, however, leads to the conclusion that these data support the notion that some response consolidation had occurred. The first source of evidence for this is the fact that intrusions were observed during the first four trials. The second is the observation that Ss of Group L looked first to the stimulus and then to the response throughout the eight trials. This type of viewing pattern is characteristic of early learning trials (response-consolidation) where 7-pair lists have been employed and where Ss later switch to a pattern of viewing the stimulus then the response then the stimulus (McCormack, Haltrecht, \& Hannah, 1966). The possibility remains, however, that the fixation functions of Group $L$ might reflect a learning strategy rather than a Stage 1 process.

Fixation functions unlike those observed in learning situations were obtained by Group P, as is evident from Fig. 1. Even though these Ss were required to pronounce the stimulus members of the CVC pairs, response-viewing was predominant throughout the eight trials. This would indicate that the initial responseviewing observed in learning settings is due to some kind of artifact such as a left-to-right reading habit. As with Group L, Group P Ss tended to look first to the stimulus and and then to the response while viewing the two together.

\section{References}

Mackworth, N. H., \& Thomas, E. L. Head-mounted eye-marke: camera. J. Opt. Soc. Amer., 1962, 52, 713-716.

McCormack, P. D., \& Haltrecht, E. J. Monitoring eye movements under two conditions of presentation of paired-associate materials. Canad. J. Psychol., 1966, 20, 154-159.

McCormack, P. D., Haltrecht, E. J., \& Hannah, T. E. Monitoring eye movements during the learning of successive paired-associate lists. J. verbal Learn. verbal Behav., in press.

Noble, C. E. Measurement of associative value $(a)$, rated associations $\left(a^{*}\right)$ and scaled meaningfulness $\left(m^{*}\right)$ for the $2100 \mathrm{CVC}$ combinations of the English alphabet. Psychol. Rep., 1961, 8, 487-521.

Underwood, B. J., \& Schulz, R. W. Meaningfulness and verbal learning. Chicago: Lippincott, 1960.

\section{Notes}

1. This research was supported by a grant-in-aid from the Associate Committee on Experimental Psychology of the National Research Council of Canada. (Grant APA-78).

2. Now at York University, Toronto, Canada. 